\title{
Glucocorticoid metabolites in newborns: a marker for traffic noise related stress?
}

Manuella Lech Cantuaria ${ }^{1 *}$, Jakob Usemann ${ }^{2,3^{*}}$, Elena Proietti ${ }^{2,3}$, Victoria Blanes-Vidal ${ }^{1}$, Bernhard Dick $^{4}$, Christa E. Flück ${ }^{5}$, Simone Rüedi ${ }^{2}$, Harris Héritier ${ }^{6,7}$, Jean-Marc Wunderli ${ }^{8}$, Philipp Latzin ${ }^{3}$, Urs Frey $^{2}$, Martin Röösli ${ }^{6,7}$, Danielle Vienneau ${ }^{6,7 \dagger}$ on behalf of the BILD ${ }^{9}$ study group

${ }^{1}$ The Maersk Mc-Kinney Moller Institute, Faculty of Engineering, University of Southern Denmark, Odense, Denmark

${ }^{2}$ University Children's Hospital Basel, University of Basel, Switzerland

${ }^{3}$ Pediatric Respiratory Medicine, Department of Pediatrics, Inselspital, Bern University Hospital, University of Bern, Switzerland

${ }^{4}$ Nephrology \& Hypertension, University of Bern, Bern, Switzerland

${ }^{5}$ Pediatric Endocrinology, Diabetology and Metabolism, Bern University Children's Hospital, Bern, Switzerland

${ }^{6}$ Swiss Tropical and Public Health Institute, Basel, Switzerland

${ }^{7}$ University of Basel, Basel, Switzerland

${ }^{8}$ Empa, Laboratory for Acoustics/Noise control, Dübendorf, Switzerland

${ }^{9}$ Basel Bern Infant Lung Development (BILD) cohort, current study group: Insa Korten, Bern; Pinelopi Anagnostopoulou, Bern; Urs Frey, Basel; Olga Gornalova, Basel; Philipp Latzin, Bern; Elena Proietti, Zurich; Jakob Usemann, Basel.

${ }^{*}$ Equal contribution.

$\dagger$ Corresponding author:

Danielle Vienneau, $\mathrm{PhD}$

Department of Epidemiology and Public Health 
Swiss Tropical and Public Health Institute

Socinstrasse 57, CH-4051, Basel, Switzerland

danielle.vienneau[at]unibas.ch

tel: $+41(0) 612848398$

fax: $+41(0) 612848105$

Short title: Road traffic noise and glucocorticoids in newborns

Manuscript word count: 3881

Abstract word count: 269

Tables: 4

Figures: 2 


\section{ABSTRACT}

Background: Traffic noise has been associated with an increased risk for several non-auditory health effects, which may be explained by a noise-induced release of stress hormones (e.g. glucocorticoids). Although several studies in children and adults have indicated an increased secretion of glucocorticoids after exposure to noise, information regarding newborns is scarce.

Objectives: To investigate the association between residential exposure to road traffic noise and postnatal stress response, as assessed by the concentration of glucocorticoids at five weeks of age.

Methods: Residential noise exposure was estimated for each infant based on spatially detailed modeled data. Adjusted multivariable linear regression models were used to estimate the association between noise exposure and the concentration of nine glucocorticoid metabolites measured in urine of 165 infants from a prospective birth cohort in Bern, Switzerland. Noise exposure (Lden, dB) was categorized into tertiles: low (reference), medium and high.

Results: Indications of a positive association were found between high road traffic noise and cortisol (\% change relative to the reference: $12.1 \%$ [95\% confidence interval: $-10.3,40.1 \%]$ ) and cortisone $(22.6 \%[-1.8,53.0 \%])$, but just the latter was borderline significant. Borderline significant associations were also found between downstream metabolites and higher road traffic noise levels; associations were found to be both positive (i.e. for $\beta$-cortolone $(51.5 \%[-0.9,131.5 \%]))$ and negative (i.e. for $\alpha$-cortolone $(-18.3 \%[-33.6,0.6 \%])$ and tetrahydrocortisol $(-23.7 \%[-42.8,1.9 \%]))$.

Conclusions: Our findings suggest a potential association between exposure to higher road traffic noise levels and changes in glucocorticoid metabolism in early postnatal life. A possible physiological relevance and associations with short- and long-term adverse health effects in a larger study population need to be further investigated.

Keywords: Road traffic; Noise; Glucocorticoids; Cortisol; Postnatal stress; Environmental stressors 


\section{Introduction}

In the past few decades, there has been a growing concern about possible health impacts of environmental noise from different sources, such as industry, neighbors and transportation. As one of the most widespread sources of environmental stress (i.e. adverse stimulus caused by environmental conditions which require adaptation or coping measurements (Campbell 1983)), noise from transportation is considered a major threat for public health. Transportation noise has been identified as a major contributor to the environmental burden of disease in Europe (Hänninen et al. 2014; WHO 2011), and a recent evaluation in Switzerland found that the burden of transportation noise (when quantified in monetary terms) was equal to that of air pollution (Vienneau et al. 2015b).

Studies have demonstrated an association between exposure to transportation noise and an increased risk for several non-auditory health effects in adults, including reduced quality of life (Dratva et al. 2010; Héritier et al. 2014), hypertension (Haralabidis et al. 2008; Paunović et al. 2014; van Kempen and Babisch 2012), ischemic heart disease (Babisch 2014; Héritier et al. 2017; Seidler et al. 2016; Sørensen et al. 2012; Vienneau et al. 2015a), respiratory health (Recio et al. 2016b), and diabetes (Eze et al. 2017; Sørensen et al. 2013). In relation to studies in children, most are focused on blood pressure (Babisch et al. 2009; Belojevic et al. 2008), cognitive function (Haines et al. 2001; Stansfeld et al. 2017) and respiratory outcomes (Ising et al. 2003, 2004a, 2004b).

Noise induced health effects are postulated to occur through the activation of either a direct or indirect pathway (Münzel et al. 2016). In the direct pathway, noise may directly trigger an instantaneous activation of the central nervous system; in the indirect pathway stress markers may be activated through annoyance (Babisch 2002). Regardless of the pathway, it is suggested that noise exposure may be associated with stress responses, characterized by activation of the neuroendocrine system (i.e. hypothalamus-pituitary-adrenal (HPA) axis and sympathetic-adrenal-medulla axis), and a subsequent release of stress hormones, e.g. glucocorticoids. 
The stimulation of glucocorticoid production results in several regulatory effects on physiological functions in the human body. The secretion of glucocorticoids induces immune responses, and might act on both the production of cytokines and lymphocyte proliferation (Dobbs et al. 1996). Overproduction of glucocorticoids also affects blood glucose levels by inhibiting insulin secretion and increases the concentration of lipids and lipoproteins (e.g. cholesterol and triglycerides) (Aich et al. 2009; Qureshi et al. 2009; Recio et al. 2016a).

A number of studies have empirically demonstrated associations between exposure to transportation noise and stress-induced secretion of glucocorticoids, mostly cortisol. For instance, Ising et al. (2004b) and Wagner et al. (2010) showed an association between elevated salivary cortisol levels and traffic noise in children and adults, respectively. Furthermore, an association between morning saliva cortisol levels in women and aircraft noise exposure above $60 \mathrm{~dB}$ was reported by Selander et al. (2009). Lefèvre et al. (2017), on the other hand, only found an association between noise and elevated evening cortisol levels, but not morning cortisol levels, in adults living in the vicinity of three large airports in France. While the association is well reported in children and adults, this has never been investigated in newborn infants who are particularly vulnerable to environmental exposures and likely to experience long term effects.

We aimed to investigate the association between residential exposure to road traffic noise (during and shortly after pregnancy) and postnatal stress responses, as assessed by the concentration of glucocorticoid metabolites measured in urine from infants at five weeks of age.

\section{Materials and Methods}

\subsection{Study design and subjects}

This study included a subgroup of 205 healthy infants from the prospective Basel-Bern Infant Lung Development (BILD) birth cohort, recruited antenatally between 2005 and 2011 in the region of 
Bern, Switzerland. We determined the residential history during pregnancy and after birth, and assessed pre- and early postnatal risk factors (e.g. tobacco smoke exposure, socio-economic status, delivery mode) (Bradley and Corwyn 2002; Floyd et al. 1993; Latimer et al. 2012; Rice et al. 2007) via standardized questionnaires (Fuchs et al. 2012). Addresses were geocoded using a reference file from the Swiss Federal Statistical Office (Neuchâtel). Exclusion criteria for the study were delivery $<35$ weeks gestational age and problems during the extraction of urine samples and/or analysis. The study was approved by the Ethics Committee of Bern, Switzerland. Written informed consent was obtained from parents before enrollment.

\subsection{Exposure assessment}

Noise exposure assessment in this study was based on detailed noise modeling for the year of 2011 from the SiRENE (Short and Long Term Effects of Traffic Noise Exposure) study. The SiRENE noise modeling and database is fully described elsewhere (Karipidis et al. 2014). In brief, emissions and propagation for road traffic noise were respectively calculated using sonROAD (Heutschi 2004) and the propagation model of StL-86 (OFPE 1987). The SiRENE database includes road traffic noise estimates in decibels $(\mathrm{dB})$ for façade points for each dwelling in every building in Switzerland. Data (VECTOR25) from the Swiss Federal Office of Topography (Swisstopo 2007) were used to characterize the buildings and dwelling units from the period of 1998 to 2006, with height and number of floors for each building estimated by a digital surface model, combined with a digital terrain model for Switzerland. Road traffic noise was calculated at a maximum of 3 façade points per building façade and floor, with a minimum spacing distance of 5 meters.

The noise exposure metrics used in our study included: Lden, i.e., the average sound level over all $24 \mathrm{~h}$ periods of a year, with a $5 \mathrm{~dB}$ penalty for the evening (19:00 - 23:00) and a $10 \mathrm{~dB}$ penalty for the night $(23: 00-07: 00)$ hours; and LeqD and LeqN, which respectively represent the average sound level over all day (07:00 - 23:00) and night (23:00 - 07:00) periods of a year. While the 
SiRENE database gives exposure estimates by floor, no residential floor information was available for the BILD study participants. We therefore assigned exposure from the middle floor of the relevant residential building (i.e. based on residential geocode only). Specifically, noise levels from the façade point with the maximum Lden for each participant were assigned, i.e. selected the most exposed façade point for the residential unit based on the Lden. Exposure variables were censored at $35 \mathrm{~dB}$ (Lden, LeqD) or $25 \mathrm{~dB}$ (LeqN) to account for background noise from diffuse sources.

Since traffic-related air pollution was shown to affect glucocorticoid metabolism (Rüedi et al. 2013), we also assessed residential nitrogen dioxide $\left(\mathrm{NO}_{2}\right.$ in $\left.\mu \mathrm{g} / \mathrm{m}^{3}\right)$ exposure averaged for the in-utero period of each infant. We estimated $\mathrm{NO}_{2}$ exposure using a time-space hybrid model specifically developed for the BILD study based on 29,000 measurements at 146 locations (during the period of 1998-2009). Predictor data included annual $\mathrm{NO}_{2}$ from dispersion models, traffic, land use and meteorological variables. The model was validated using passive measurements at participant's homes, with validation $\mathrm{R}^{2}$ s ranging from 0.54 in rural areas to 0.67 in urban areas (Proietti et al. 2016).

\subsection{Outcome assessment}

To assess urinary glucocorticoid levels, parents presented to University Hospital of Bern, Switzerland, with their infant at five weeks of age (hereby referred as "newborns") for a routine clinical visit (Fuchs et al. 2012). A cotton pad was placed into the regular diaper from which the urine spot was extracted by study nurses. Within 24 hours, the urine was centrifuged out from the cotton pad at $4378 \mathrm{rpm}$ for 8 minutes at room temperature (Multifuge 3SR+, Thermo Fisher Scientific) and immediately stored at $-20^{\circ} \mathrm{C}$. After sample processing (i.e. pre-extraction, enzymatic hydrolysis, extraction from the hydrolysis mixture, derivatization, gel filtration), gas chromatography-mass spectrometry was carried out to quantitate the different stress hormones as previously described (Dhayat et al. 2015; Garde et al. 2004; Shackleton 1986). This work was 
conducted at the Department of Nephrology, Hypertension and Clinical Pharmacology, University Hospital of Bern, Switzerland, using a gas chromatograph 7890A from Agilent Technologies (La Jolla, California, USA) coupled to a mass selective detector (Hewlett-Packard 5975C). Measured steroids were then standardized to urinary creatinine concentration (QuantiChrom Creatinine Assay, DICT-500; BioAssay Systems, Hayward, CA, USA) and expressed in $\mu \mathrm{g} / \mathrm{mmol}$ creatinine (Dhayat et al. 2015; Garde et al. 2004). Validity and stability of this urine collection method for steroid analyses have been previously reported (Heckmann et al. 2005; Mazzarino et al. 2011; Thomas 2010). Minimal urine volume required for steroid analysis was $200 \mu \mathrm{l}$, standard volume was $1.5 \mathrm{ml}$; for creatinine measurement $5 \mu 1$ urine was used. The assay variability for the steroid metabolites was between 15-22\%, as previously reported (N'Gankan et al. 2002; Quattropani et al. 2001; Vogt et al. 2002).

\subsection{Statistical analysis}

We restricted our analysis to the nine glucocorticoid metabolites that were detectable in our study population: eight were detectable in the urine of all the study newborns (cortisol, cortisone, $5 \alpha$ tetrahydrocortisol ( $\alpha$-THF), tetrahydrocortisol (THF), $\alpha$-cortol, tetrahydrocortisone (THE), $\alpha$ cortolone and $\beta$-cortolone) and the ninth had negligible missing data ( $\beta$-cortol, for which only two of 165 observations were missing). Since the distribution of concentrations for many of the glucocorticoid metabolites was strongly right-skewed, data were normalized by natural logarithmic transformation.

Multivariable linear regression models were used to evaluate the association between road traffic noise and: 1) the concentration of each glucocorticoid metabolite; 2) the sum of cortisol (the most abundant endogenous glucocorticoid and primary hormone responsible for stress responses) and cortisone (the inactive form); 3) the total sum of the nine glucocorticoid metabolites measured. The 
noise exposure variables were categorized into tertiles (subsequently referred to as "low", "medium" and "high" categories).

All models were calculated unadjusted (i.e. crude), adjusted for anthropometric factors including sex, gestational age and weight at the time of urine sample (i.e. basic) and further adjusted for potential confounders (i.e. full) identified in previous studies as relevant risk factors (Dhayat et al. 2015; Rüedi et al. 2013): delivery mode; pathological cardiotocogram (CTG); maternal smoking during pregnancy; educational status of the mother; season at birth; vaginal infection; maternal atopy; $\mathrm{NO}_{2}$ exposure during pregnancy; and existence of older siblings. We used backwards step selection, retaining all statistically significant variables $(\mathrm{p}<0.1)$ or variables that, when removed, changed the risk estimate by at least $10 \%$ of the previous value.

Associations were considered statistically significant when $p$-value $<0.05$ and borderline statistically significant when $0.05 \leq \mathrm{p}$-value $<0.1$. All statistical analyses were performed in $\mathrm{R}$ software (version 3.1.2).

\section{Results}

\section{1 Summary statistics}

From the 205 enrolled newborns, we excluded those with low gestational age $(n=2)$, jellified urine samples $(n=35)$ and unreadable chromatogram $(n=3)$, giving a total sample of $165(80.5 \%)$ newborns. Of those, $88(53 \%)$ were male, the mean (SD) gestational age was $39.5(1.3)$ weeks and weight at the time of the urine sample was $4.3(0.6) \mathrm{kg}$. There were $21 \%$ of the newborns delivered by Cesarean section and 5\% of the mothers smoked during pregnancy (Table 1). The median longterm exposure to road traffic noise was $52.4 \mathrm{~dB}(\mathrm{~A})$ for $\mathrm{LeqD}, 45.6 \mathrm{~dB}(\mathrm{~A})$ for LeqN and $54.4 \mathrm{~dB}$ Lden (Table 2). The exposure distribution (for Lden) for the study population was similar compared to the general population, especially in the high category population (data not shown). The cortisol 
and cortisone concentration (in $\mu \mathrm{g} / \mathrm{mmol}$ creatinine) measured from urine were 109.5 (72.4) and 352.8 (205.8), respectively. Details on the 9 glucocorticoid metabolites are provided in Table 3. It should be noted that compared to glucocorticoid levels measured in another health study population (Dhayat et al. 2015) the levels in our cohort were systematically higher (Table 3). Reasons underlying this difference may be due to different sampling strategies.

$<<$ Table 1 hereabouts $>>$

$<<$ Table 2 hereabouts $>>$

$<<$ Table 3 hereabouts $>>$

Noise and $\mathrm{NO}_{2}$ exposure during pregnancy showed low correlation coefficients $(\mathrm{r}=0.33$ for all exposure metrics, i.e. LeqD, LeqN and Lden). Additionally, all noise exposure metrics were highly correlated with each other (Pearson's correlation (r) ranged between 0.99 and 1.00). Therefore, association results between glucocorticoid concentration and noise are only shown for Lden, as it is the aggregated noise metric, representing noise levels over all $24 \mathrm{hr}$ periods in a year.

\subsection{Association between road traffic noise (Lden) and glucocorticoid metabolite concentration}

Though not statistically significant, we observed indications of a positive association between road traffic noise exposure in the high category compared to low (reference) exposure category with cortisol $(\%$ change $=12.1 \%$ [95\%CI: $-10.3,40.1 \%], \mathrm{p}$-value $=0.316)$. Newborns exposed in the high noise category showed borderline significant higher levels of cortisone compared to the reference $(22.6 \%[-1.8,53.0]$, p-value $=0.074)($ Figure 1, Table 4). For the downstream metabolites, road traffic noise exposure was shown to be borderline associated with higher concentrations of $\beta$ cortolone for newborns in the high exposed category $(51.5 \%[-0.9,131.5]$, p-value $=0.057)$, whereas the borderline associations were in the opposite direction for $\alpha$-cortolone $(-18.3 \%[-33.6,0.6], \mathrm{p}$ value $=0.059)$ and THF $(-23.7 \%[-42.8,1.9], \mathrm{p}$-value $=0.069)$ concentrations. 
Our findings also indicate a positive relationship between noise in the high exposure category, compared to the reference, and the sum of cortisol and cortisone, although this was not statistically significant $(\mathrm{p}=0.103)$. We found no association between noise exposure and the total sum of the nine glucocorticoids. In general, similar results were obtained for the crude and basic models (Table 4).

\author{
$<<$ Figure 1 hereabouts $>>$ \\ $<<$ Table 4 hereabouts $>>$
}

\title{
4. Discussion
}

In this study of healthy newborns, we found some indications of associations between higher road traffic noise exposure as an environmental stressor and several of the glucocorticoids measured in urine; these associations were only borderline statistically significant. Overall steroid production, as assessed by the sum of the nine glucocorticoid metabolites, was not associated with higher road traffic noise exposure. On the other hand, we found a non-significant but positive relationship between higher road traffic noise and the sum of cortisol and cortisone.

Cortisol is produced in the adrenal cortex after stimulation through the HPA axis (Figure 2). This hormone is the most relevant glucocorticoid in humans since it is the main substrate which exerts biological effects by binding to the glucocorticoid receptor. The biological inactive form of cortisol is cortisone, but the two are interconvertible. The conversion between the two metabolites is achieved in many peripheral tissues by two enzymes: $11 \beta$-hydroxysteroid dehydrogenase (HSD) type 1 converts cortisol to cortisone, and $11 \beta$-HSD type 2 does the opposite. These glucocorticoids are metabolized to downstream products and excreted in the urine (Dhayat et al. 2015; Oakley and Cidlowski, 2013). 
Compared to the reference, we found exposure in the highest road traffic noise category was borderline significantly associated with higher concentrations of cortisone only; cortisol was not associated with higher noise levels though the point estimate was also positive. That one of these metabolites is borderline significant may indicate that road traffic noise may increase glucocorticoid production, suggesting a potential activation of the HPA axis, as proposed by previous studies (Ising et al. 2004b; Lefèvre et al 2017; Selander et al. 2009; Wagner et al. 2010). However, we also investigated downstream metabolites and found no robust increase. We found borderline significant positive associations between higher road traffic noise and $\beta$-cortolone concentration, while borderline significant negative associations were found for THF and $\alpha$-cortolone.

$<<$ Figure 2 hereabouts $>>$

There are several mechanisms which can modify glucocorticoid concentrations at the level of production or metabolism. These include expression and activation of enzymes that catalyze substrate to product conversions in the steroid pathways (Miller and Auchus 2011). It could be speculated that noise exposure modifies the amount of glucocorticoid production by directly changing the HPA axis activity. This hypothesis seems rather unlikely since the total amount of steroids (as assessed by the sum of the nine glucocorticoids) did not increase. It may rather be that noise exposure modifies the enzymes' activity indirectly. For example, noise exposure could change the levels of reactive oxygen species (ROS), which may further modify glucocorticoid biosynthesis. This has been previously shown by Ohlemiller et al. (1999) who observed increased ROS activity in the cochlear after noise exposure. As this hypothesis cannot be directly confirmed from our data, further mechanistic studies are recommended to assess how noise exposure causes its effects.

The precise exposure window related to the changes in glucocorticoid concentrations observed in our study is still unclear, i.e. whether the change in concentrations was related to maternal stress responses during pregnancy or stressful events in early infancy. Regardless of the uncertainty about 
the relevant exposure time, our results indicate that newborn infants exposed to higher levels of road traffic noise had borderline significant higher levels of the main glucocorticoid metabolite cortisone. This could indicate that road traffic noise exposure may act as a potential environmental stressor in early postnatal life. It is worthwhile noting that other stressful factors, e.g. birth events, may also produce effects on the HPA axis.

It remains unclear if our findings have a possible physiological relevance later in life. It has been previously suggested that both fetal and early postnatal life environment are important determinants of some diseases in adults. Although exposure to higher levels of glucocorticoids may result in beneficial short-term metabolic consequences, excess is related to increased blood pressure and alterations of the glucose metabolism in the long term (Edwards et al. 1996). These effects can persist and increase the risk of cardiovascular, metabolic, neuroendocrine and behavioral disorders later in life (Barker 1995; Barker et al. 1989; Seckl 2001). Studies in rats have suggested that increased fetal exposure to glucocorticoids may explain higher risks of hypertension (Benediktsson et al. 1993), diabetes (Nyirenda et al. 1998) and endocrine system alterations (Barbazanges et al. 1996) in adulthood.

\section{Strengths and limitations}

One of the main strengths of our study is the standardized assessment of detailed prenatal risk factors, enabling us to control for potential confounders. Glucocorticoid measurements were all performed at the same time point (five weeks of age), eliminating a known age-dependent impact on measurements (Dhayat et al. 2015). The exact time (hour) of day for the urine sampling was not standardized. However, as neonates do not have the typical adult-type day-night rhythm at the age investigated (Iwata et al. 2013) we consider that our sampling method did not influence our findings. Measurements included a large batch of glucocorticoid metabolites, rather than only one prominent metabolite, e.g. cortisol. This batch analysis correlates well with the entire amount of glucocorticoids 
in the body, and represents well the infants' physiological stress response due to road traffic noise, as assessed in this study.

Our multivariable linear regression models were adjusted for air pollution which, while not highly correlated in our study, can be correlated with traffic noise due to the common source. We also used spatially detailed noise and air pollution models in assigning individual level exposures at the home address. Due to the high correlation among the noise metrics (Pearson's correlation $>0.99$ for all combinations of LeqD, LeqN and Lden), we cannot assess if day or night exposure is more influential on change in glucocorticoid concentrations. Our exposure further represents the longerterm average rather than road traffic noise specifically for pregnancy and five weeks after birth. This is considered adequate given that daily fluctuations in noise levels are similar day-to-day, and noise is less influenced by meteorology than air pollution. Further, it was not feasible to employ spot noise measurements for this study. We also did not have information on the working address of the mother during pregnancy. However, in this study we assume that night-time noise is most critical for potential health effects during the pre-natal period. It seems unlikely that noise at work is strongly correlated to night-time noise (except through factors already included in the confounding adjustments) and thus confounding from noise at work is unlikely to be relevant for our analysis. Additionally, data on perinatal and early postnatal noise exposure was not available; but, as we only included healthy newborns in our cohort without complications during delivery, the average stay in the hospital was only 1-3 days. Therefore, the impact of noise exposure during this short time interval, compared to the whole study period, was likely not very substantial.

Detailed information on the floor where the residence was located was not available, reducing precise assessment of the noise exposure. However, as illustrated by Karipidis et al. (2014), noise levels on the highest exposed side of a typical residential building change only slightly with floor height. Further, only $13.3 \%$ participants resided in buildings taller than three floors, thus our assumption of the middle building floor is reasonable for most participants. As in most studies, noise 
exposure was only assessed at home and we further did not have information on window opening behavior, placement of the infant's sleeping room, or amount of time spent outside the home. This last point is less relevant for the newborns included in this study since healthy babies in Switzerland are typically cared for by mothers at home after a brief hospital stay. Mothers and infants may of course spend some daytime hours outdoors, but we also adjusted for season of birth to account for potential differences in exposure due to outdoor activity and window opening behavior.

It may also be viewed as a limitation that glucocorticoid metabolites were assessed at one time point ( 5 weeks of age), and are therefore just snap-shot. This should be considered in the interpretation of our results, given the possible short-term physiologic alterations during the first year of life (Dhayat et al. 2015). Only by longitudinal assessment of exposure based on measurements, in line with repeated measurements of glucocorticoid metabolites, are conclusions on a sustained and physiologically relevant effect of road traffic noise exposure upon glucocorticoid metabolites possible. Finally, we recognize our small sample size which may explain the large confidence intervals and borderline significant associations.

\section{Conclusions}

Though not reaching statistical significance, our study suggests a potential relationship between road traffic noise exposure and glucocorticoid metabolism in early postnatal life. Further prospective studies in larger pediatric samples are needed to better understand the clinical relevance of our indicative findings, especially in subjects exposed to high noise levels where potential adverse effects may be more relevant.

\section{DECLARATIONS:}

Ethics approval and consent to participate: 
The study was approved by the Ethics Committee of Bern, Switzerland. Written informed consent was obtained from parents before enrollment.

Competing interests:

The authors declare that they have no competing interests.

Authors' contributions:

UF, PL, DV, MR study concept; MLC, JU, EP, DV, MR study design; MLC, JU, EP literature review; JW noise model; HH, MLC, DV exposure assessment; BD, CF, SR laboratory anayses; MLC, JU, DV statistical and data analysis; MLC, JU, VBV, UF, MR, DV data interpretation; MLC, JU, DV write and revise manuscript; all review and comment on manuscript.

Funding:

This work was undertaken within the framework of SiRENE and BILD studies, which are both financially supported by the Swiss National Science Foundation, grant number 320030_163311 (BILD) and CRSII3_147635 (SiRENE). We would also like to thank the National Council for Scientific and Technological Development $(\mathrm{CNPq})$, Brazil for the financial support for the studentship project.

Acknowledgements:

Our acknowledgements are also extended to Professor Brigitte M. Frey from the Department of Nephrology, Hypertension and Clinical Pharmacology at the Inselspital, Bern University Hospital 
(University of Bern) and all the members of SiRENE and BILD teams for all scientific and relevant inputs to the study. 


\section{References}

Aich P, Potter A, Griebel P. 2009. Modern approaches to understanding stress and disease susceptibility: A review with special emphasis on respiratory disease. Int J Gen Med 2:19-32.

Babisch W. 2002. The noise/stress concept, risk assessment and research needs. Noise Health 4:1-10.

Babisch W, Neuhauser H, Thamm M, Seiwert M. 2009. Blood pressure of 8-14 year old children in relation to traffic noise at home - Results of the German Environmental Survey for Children (GerES IV). Sci Total Environ 407:5839-5843; doi:10.1016/j.scitotenv.2009.08.016.

Babisch W. 2014. Updated exposure-response relationship between road traffic noise and coronary heart diseases: A meta-analysis. Noise Health 16:1-9.

Barbazanges A, Piazza P V, Le Moal M, Maccari S. 1996. Maternal glucocorticoid secretion mediates longterm effects of prenatal stress. J Neurosci 16:3943-9.

Barker DJ, Osmond C, Golding J, Kuh D, Wadsworth ME. 1989. Growth in utero, blood pressure in childhood and adult life, and mortality from cardiovascular disease. BMJ 298:564-567; doi:10.1136/bmj.298.6673.564.

Barker DJ. 1995. Fetal origins of coronary heart disease. BMJ 311:171-174; doi:10.1136/bmj.311.6998.171.

Belojevic G, Jakovljevic B, Stojanov V, Paunovic K, Ilic J. 2008. Urban road-traffic noise and blood pressure and heart rate in preschool children. Environ Int 34:226-231; doi:10.1016/j.envint.2007.08.003.

Benediktsson R, Lindsay RS, Noble J, Seckl JR, Edwards CRW. 1993. Glucocorticoid exposure in utero: new model for adult hypertension. Lancet 341:339-341; doi:10.1016/0140-6736(93)90138-7.

Bradley RH, Corwyn RF. 2002. Socioeconomic Status and Child Development. Annu Rev Psychol 53:371399.

Campbell JM. 1983. Ambient Stressors. Environ Behav 15: 355-380.

Dhayat NA, Frey AC, Frey BM, d'Uscio CH, Vogt B, Rousson V, et al. 2015. Estimation of reference curves for the urinary steroid metabolome in the first year of life in healthy children: Tracing the complexity of human postnatal steroidogenesis. J Steroid Biochem Mol Biol 154:226-236; doi:10.1016/j.jsbmb.2015.07.024.

Dobbs CM, Feng N, Beck FM, Sheridan JF. 1996. Neuroendocrine regulation of cytokine production during experimental influenza viral infection: effects of restraint stress-induced elevation in endogenous corticoste- rone. J Immunol 157:1870-1877.

Dratva J, Zemp E, Dietrich DF, Bridevaux P-O, Rochat T, Schindler C, et al. 2010. Impact of road traffic noise annoyance on health-related quality of life: results from a population-based study. Qual Life Res 19:37-46; doi:10.1007/s11136-009-9571-2.

Edwards CRW, Benediktsson R, Lindsay RS, Seck1 JR. 1996. 11ß-Hydroxysteroid dehydrogenases: Key enzymes in determining tissue-specific glucocorticoid effects. Steroids 61:263-269; doi:10.1016/0039128X(96)00033-5.

Eze IC, Foraster M, Schaffner E, Vienneau D, Héritier H, Rudzik F, et al. 2017. Long-term exposure to transportation noise and air pollution in relation to incident diabetes in the SAPALDIA study. Int $\mathrm{J}$ Epidemiol 1-11; doi:10.1093/ije/dyx020.

Floyd R, Rimer B, Giovino G. 1993. A review of smoking in pregnancy: effects on pregnancy outcomes and cessation efforts. Annu Rev Public Health 14:379-411.

Fuchs O, Latzin P, Kuehni CE, Frey U. 2012. Cohort profile: The Bern Infant Lung Development cohort. Int J Epidemiol 41:366-376; doi:10.1093/ije/dyq239.

Garde AH, Hansen ÅM, Kristiansen J, Knudsen LE. 2004. Comparison of Uncertainties Related to Standardization of Urine Samples with Volume and Creatinine Concentration. Ann Occup Hyg 48:171179; doi:10.1093/annhyg/meh019. 
Haines M, Stansfeld SA, Job RFS, Berglund B, Head J. 2001. Chronic aircraft noise exposure, stress responses, mental health and cognitive performance in school children. Psychol Med 31:265-277; doi:10.1017/S0033291701003282.

Hänninen O, Knol AB, Jantunen M, Lim T-A, Conrad A, Rappolder M, et al. 2014. Environmental Burden of Disease in Europe: Assessing Nine Risk Factors in Six Countries. Environ Health Perspect 122:439446; doi:10.1289/ehp.1206154.

Haralabidis AS, Dimakopoulou K, Vigna-Taglianti F, Giampaolo M, Borgini A, Dudley ML, et al. 2008. Acute effects of night-time noise exposure on blood pressure in populations living near airports. Eur Heart J 29:658-664; doi:10.1093/eurheartj/ehn013.

Heckmann M, Hartmann MF, Kampschulte B, Gack H, Bödeker R-H, Gortner L, et al. 2005. Assessing cortisol production in preterm infants: Do not dispose of the nappies. Pediatr Res 57:412-418; doi:10.1203/01.PDR.0000153947.51642.C1.

Héritier H, Vienneau D, Frei P, Eze IC, Brink M, Probst-Hensch N, et al. 2014. The association between road traffic noise exposure, annoyance and health-related quality of life (HRQOL). Int J Environ Res Public Health 11:12652-12667; doi:10.3390/ijerph111212652.

Héritier H, Vienneau D, Foraster M, Eze IC, Schaffner E, Thiesse L, et al. 2017. Transportation noise exposure and cardiovascular mortality: a nationwide cohort study from Switzerland. Eur J Epidemiol; doi:10.1007/s10654-017-0234-2.

Heutschi K. 2004. Son Road: New Swiss road traffic noise model. Acta Acust United with Acust 90: 548554.

Ising H, Lange-Asschenfeldt H, Lieber GF, Weinholdt H, Eilts M. 2003. Respiratory and dermatological diseases in children with long-term exposure to road traffic immisions. Noise Health 5:41-50.

Ising H, Lange-Asschenfeldt H, Lieber GF, Moriske HJ, Weinholdt H. 2004a. Exposure to traffic related air pollution and noise and the development of respiratory diseases in children. J Child Health 2:145-147; doi: 10.3109/15417060490906477.

Ising H, Lange-Asschenfeldt H, Moriske HJ, Born J, Eilts M. 2004b. Low Frequency noise and stress: Bronchitis and cortisol in children exposed chronically to traffic noise and exhaust fumes. Noise Health 6:21-28.

Iwata O, Okamura H, Saitsu H, Saikusa M, Kanda H, Eshima N, et al. 2013. Diurnal Cortisol Changes in Newborn Infants Suggesting Entrainment of Peripheral Circadian Clock in Utero and at Birth. J Clin Endocrinol Metab 98:E25-E32; doi:10.1210/jc.2012-2750.

Karipidis I, Vienneau D, Habermacher M, Köpfli M, Brink M, Probst-Hensch N, et al. 2014. Reconstruction of historical noise exposure data for environmental epidemiology in Switzerland within the SiRENE project. Noise Mapp 1:3-14; doi:10.2478/noise-2014-0002.

Latimer K, Wilson P, Kemp J, Thompson L, Sim F, Gillberg C, et al. 2012. Disruptive behaviour disorders: A systematic review of environmental antenatal and early years risk factors. Child Care Health Dev 38:611-628; doi:10.1111/j.1365-2214.2012.01366.x.

Lefèvre M, Carlier M, Champelovier P, Lambert J, Laumon B, Evrard A, et al. 2017. Effects of aircraft noise exposure on saliva cortisol near airports in France. Occup Environ Med 1-8; doi:10.1136/oemed-2016104208.

Mazzarino M, Abate MG, Alocci R, Rossi F, Stinchelli R, Molaioni F, et al. 2011. Urine stability and steroid profile: Towards a screening index of urine sample degradation for anti-doping purpose. Anal Chim Acta 683:221-226; doi:10.1016/j.aca.2010.10.003.

Miller WL, Auchus RJ. 2011. The molecular biology, biochemistry, and physiology of human steroidogenesis and its disorders. Endocr Rev 32:81-151; doi:10.1210/er.2010-0013.

Münzel T, Sørensen M, Gori T, Schmidt FP, Rao X, Brook FR, et al. 2016. Environmental stressors and cardio-metabolic disease: part II-mechanistic insights. Eur Heart J 38: 557-564; doi:10.1093/eurheartj/ehw294. 
N'Gankam V, Uehlinger D, Dick B, Frey BM, Frey FJ. 2002. Increased cortisol metabolites and reduced activity of $11 \beta$-hydroxysteroid dehydrogenase in patients on hemodialysis. Kidney Int 61:1859-1866; doi:10.1046/j.1523-1755.2002.00308.x.

Nyirenda MJ, Lindsay RS, Kenyon CJ, Burchell A, Seck1 JR. 1998. Glucocorticoid exposure in late gestation permanently programs rat hepatic phosphoenolpyruvate carboxykinase and glucocorticoid receptor expression and causes glucose intolerance in adult offspring. J Clin Invest 101:2174-2181; doi:10.1172/jci1567.

Oakley R, Cidlowski JA. 2013. The Biology of the Glucocorticoid Receptor: New Signaling Mechanism in Health and Disease. J Allergy Clin Inmunol 132:1033-1044; doi:10.1016/j.jaci.2013.09.007.

Office fédéral de la protection de l'environnement (OFPE). 1987. Modèle de Calcul de Bruit du Trafic Routier Pour Ordinateur, 1ère partie: Manuel d'utilisation du logiciel STL-86 version 1.0.

Ohlemiller KK, Wright JS, Dugan LL. 1999. Early Elevation of Cochlear Reactive Oxygen Species following Noise Exposure. Audiol. Neuro-Otology 4:229-236; doi:10.1159/000013846.

Paunović K, Stojanov V, Jakovljević B, Belojević G. 2014. Thoracic bioelectrical impedance assessment of the hemodynamic reactions to recorded road-traffic noise in young adults. Environ Res 129:52-58; doi:10.1016/j.envres.2014.01.001.

Proietti E, Delgado-Eckert E, Vienneau D, Stern G, Tsai M-Y, Latzin P, et al. 2016. Air pollution modelling for birth cohorts: a time-space regression model. Environ Health 15:1-9; doi:10.1186/s12940-016-01459.

Quattropani C, Vogt B, Odermatt A, Dick B, Frey BM, Frey FJ. 2001. Reduced activity of 11 betahydroxysteroid dehydrogenase in patients with cholestasis. J Clin Invest 108:1299-1305; doi:10.1172/JCI12745.

Qureshi GM, Seehar GM, Zardari MK, Pirzado ZA, Abbasi SA. 2009. Study of blood lipids, cortisol and haemodynamic variations under stress in male adults. J Ayub Med Coll Abbottabad 21: 158-161.

Recio A, Linares C, Banegas JR, Díaz J. 2016a. Road traffic noise effects on cardiovascular, respiratory, and metabolic health: An integrative model of biological mechanisms. Environ Res 146:359-370; doi:10.1016/j.envres.2015.12.036.

Recio A, Linares C, Banegas JR, Díaz J. 2016b. The short-term association of road traffic noise with cardiovascular, respiratory, and diabetes-related mortality. Environ Res 150:383-390; doi:10.1016/j.envres.2016.06.014.

Rice F, Lewis A, Harold G, van den Bree M, Boivin J, Hay DF, et al. 2007. Agreement between maternal report and antenatal records for a range of pre and peri-natal factors: The influence of maternal and child characteristics. Early Hum Dev 83:497-504; doi:10.1016/j.earlhumdev.2006.09.015.

Rüedi S, Proietti E, Gorlanova O, Dick B, Flück C, Röösli M, et al. 2013. Effect of air pollution exposure during pregnancy on the steroid profile of newborns. Eur Respir J 42:401.

Seckl JR. 2001. Glucocorticoid programming of the fetus; adult phenotypes and molecular mechanisms. Mol Cell Endocrinol 185:61-71; doi:10.1016/S0303-7207(01)00633-5.

Seidler A, Wagner M, Schubert M, Dröge P, Pons-kühnemann J, Swart E, et al. 2016. Myocardial infarction risk due to aircraft, road and rail traffic noise Results of a case-control study based on secondary data. Dtsch Arztebl Int 113:407-414; doi:10.3238/arztebl.2016.0407.

Selander J, Bluhm G, Theorell T, Pershagen G, Babisch W, Seiffert I, et al. 2009. Saliva cortisol and exposure to aircraft noise in six European countries. Environ Health Perspect 117:1713-1717; doi:10.1289/ehp.0900933.

Stansfeld SA, Berglund B, Clark C, Lopez-Barrio I, Fischer P, Öhrström E, et al. 2017. Aircraft and road traffic noise and children's cognition and health: a cross-national study. Lancet 365:1942-1949; doi:10.1016/S0140-6736(05)66660-3.

Shackleton CHL. 1986. Profiling steroid hormones and urinary steroids. J Chromatogr 379:91-156. 
Swisstopo. 2007. VECTOR 25 Das digitale Landschaftsmodell der Schweiz. Wabern: Bundesamt für Landestopografie. Available: http://www.geo.uzh.ch/microsite/geo243/pdfs/data/vector25infode.pdf [accessed: 15 November 2016]

Sørensen M, Andersen ZJ, Nordsborg RB, Jensen SS, Lillelund KG, Beelen R, et al. 2012. Road traffic noise and incident myocardial infarction: A prospective cohort study. PLoS One 7:1-7; doi:10.1371/journal.pone.0039283.

Sørensen M, Andersen ZJ, Nordsborg RB, Becker T, Tjønneland A, Overvad K, et al. 2013. Long-term exposure to road traffic noise and incident diabetes: A cohort study. Environ Health Perspect 121:217222; doi:10.1289/ehp.1205503.

Thomas KA. 2010. 6-Sulfatoxymelatonin collected from infant diapers: Feasibility and implications for urinary biochemical markers. Biol Res Nurs 11:288-292; doi:10.1177/1099800409337330.

van Kempen E, Babisch W. 2012. The quantitative relationship between road traffic noise and hypertension: a meta-analysis. J Hypertens 30: 1075-1086.

Vienneau D, Schindler C, Perez L, Probst-Hensch N, Röösli M. 2015a. The relationship between transportation noise exposure and ischemic heart disease: A meta-analysis. Environ Res 138:372-380; doi:10.1016/j.envres.2015.02.023.

Vienneau D, Perez L, Schindler C, Lieb C, Sommer H, Probst-Hensch N, et al. 2015b. Years of life lost and morbidity cases attributable to transportation noise and air pollution: A comparative health risk assessment for Switzerland in 2010. Int $J$ Hyg Environ Health 218:514-521; doi:10.1016/j.ijheh.2015.05.003.

Vogt B, Dick B, Marti H-P, Frey FJ, Frey BM. 2002. Reduced 11beta-hydroxysteroid dehydrogenase activity in experimental nephrotic syndrome. Nephrol Dial Transplant 17:753-758; doi:10.1093/ndt/17.5.753.

Wagner J, Cik M, Marth E, Santner BI, Gallasch E, Lackner A, et al. 2010. Feasibility of testing three salivary stress biomarkers in relation to naturalistic traffic noise exposure. Int J Hyg Environ Health 213:153155; doi:10.1016/j.ijheh.2009.08.004.

World Health Organization (WHO). 2011. Burden of disease from environmental noise: Quantification of healthy life years lost in Europe. Copenhagen: World Health Organization. Available: http://www.euro.who.int/_data/assets/pdf_file/0008/136466/e94888.pdf [accessed 30 January 2017] 
Table 1: Demographic data for the 165 newborns.

\begin{tabular}{|c|c|}
\hline & Summary statistics \\
\hline \multicolumn{2}{|l|}{ Anthropometric data } \\
\hline Gestational age at birth (weeks) $^{a}$ & $39.5 \pm 1.3$ \\
\hline Weight at the time of urine collection $(\mathrm{kg})^{\text {a }}$ & $4.3 \pm 0.6$ \\
\hline Length at the time of urine collection $(\mathrm{cm})^{a}$ & $54.2 \pm 2.0$ \\
\hline Sex $(\text { male })^{b}$ & $88(53)$ \\
\hline \multicolumn{2}{|l|}{ Family history } \\
\hline Maternal education (low) ${ }^{\mathrm{b}}$ & $30(18)$ \\
\hline Maternal education (medium) ${ }^{\mathrm{b}}$ & $56(34)$ \\
\hline Maternal education (high) ${ }^{b}$ & $79(48)$ \\
\hline Older siblings ${ }^{\mathrm{b}}$ & $97(59)$ \\
\hline Pregnancy history & - \\
\hline Caesarean section ${ }^{\mathrm{b}}$ & $34(21)$ \\
\hline Vaginal infection during pregnancy ${ }^{\mathrm{b}}$ & $42(25)$ \\
\hline Maternal smoking during pregnancy ${ }^{\mathrm{b}}$ & $8(5)$ \\
\hline Pathological cardiotocogram ${ }^{\mathrm{b}}$ & $18(11)$ \\
\hline $\mathrm{NO}_{2}$ exposure during pregnancy $\left(\mu \mathrm{g} / \mathrm{m}^{3}\right)^{\mathrm{a}}$ & $17.1 \pm 5.3$ \\
\hline
\end{tabular}

Notes:

${ }^{a}$ Result is given in mean \pm standard deviation

${ }^{b}$ Result is given in number (\%) 
Table 2: Noise exposure data for the 165 newborn.

\begin{tabular}{|lccccc|}
\hline & Median & IQR & \multicolumn{3}{c|}{ Range for tertiles } \\
& & & T1 & T2 & T3 \\
LeqD (day) road noise exposure (dB(A)) & 52.4 & $45.4-57.9$ & $35.0-46.8$ & $46.9-56.2$ & $56.3-69.5$ \\
LeqN (night) road noise exposure (dB(A)) & 45.6 & $38.2-50.7$ & $25.0-39.5$ & $39.6-49.0$ & $49.1-62.4$ \\
Lden road noise exposure (dB) & 54.4 & $47.0-59.6$ & $35.0-48.4$ & $48.5-57.9$ & $58.0-71.2$ \\
\hline
\end{tabular}


Table 3: Glucocorticoid metabolite concentrations (in $\mu \mathrm{g} / \mathrm{mmol}$ creatinine) in newborns.

\begin{tabular}{|lcc|}
\hline Metabolite $^{\text {a }}$ & Mean \pm SD & IQR \\
Cortisol & $109.5 \pm 72.4$ & $63.2-122.6$ \\
Cortisone & $352.8 \pm 205.8$ & $196.4-461.0$ \\
$5 \alpha$-Tetrahydrocortisol $(\alpha-T H F)$ & $55.8 \pm 53.6$ & $23.0-75.2$ \\
Tetrahydrocortisol (THF) & $31.1 \pm 63.1$ & $12.7-28.2$ \\
$\alpha-C o r t o l$ & $181.3 \pm 178.8$ & $64.6-233.6$ \\
$\beta$-Cortol & $72.3 \pm 109.3$ & $33.4-70.4$ \\
Tetrahydrocortisone (THE) & $1632.0 \pm 844.4$ & $986.0-2053.0$ \\
$\alpha$-Cortolone & $227.8 \pm 125.0$ & $139.2-298.6$ \\
$\beta$-Cortolone & $691.6 \pm 395.1$ & $413.8-917.4$ \\
\hline
\end{tabular}

Notes:

a. Glucocorticoid metabolite concentrations were measured for all newborns $(n=165)$, except for $\beta$-cortol (n $=163)$ 
Table 4: Association between road traffic noise (determined by Lden) and concentrations of glucocorticoid metabolites ${ }^{\text {a }}$

\begin{tabular}{|c|c|c|c|c|c|c|c|}
\hline \multirow{2}{*}{$\begin{array}{l}\text { Cortisol } \\
\text { metabolite }\end{array}$} & & \multicolumn{2}{|c|}{$\begin{array}{c}\text { Crude model } \\
\text { Noise exposure (Lden) level } \\
\end{array}$} & \multicolumn{2}{|c|}{$\begin{array}{c}\text { Basic model }^{b} \\
\text { Noise exposure }\left(\text { Lden) level }^{d}\right.\end{array}$} & \multicolumn{2}{|c|}{$\begin{array}{c}\text { Adjusted model }^{\mathrm{c}} \\
\text { Noise exposure (Lden) level }^{\mathrm{d}}\end{array}$} \\
\hline & & Medium & High & Medium & High & Medium & High \\
\hline \multirow[t]{2}{*}{ Cortisol } & \%change & $2.8(-16.2,26.1)$ & $15.9(-5.7,42.5)$ & $3.8(-15.1,26.9)$ & $15.2(-6.5,41.9)$ & $0.1(-19.2,24.0)$ & $12.1(-10.3,40.1)$ \\
\hline & p-value & 0.795 & 0.162 & 0.717 & 0.185 & 0.991 & 0.316 \\
\hline \multirow[t]{2}{*}{ Cortisone } & $\%$ change & $4.6(-14.7,28.1)$ & $22.4(-0.3,50.2)$ & $5.5(-13.8,29.1)$ & $22.8(-0.4,51.3)$ & $2.8(-16.9,27.2)$ & $22.6(-1.8,53.0)$ \\
\hline & p-value & 0.666 & 0.055 & 0.604 & 0.056 & 0.797 & 0.074 \\
\hline \multirow{2}{*}{$\begin{array}{l}5 \alpha \text {-Tetrahydrocortisol } \\
(\alpha-T H F)\end{array}$} & $\%$ change & $-6.47(-31.4,27.5)$ & $-2.7(-28.8,33.0)$ & $-6.7(-31.8,27.5)$ & $-4.4(-30.8,32.2)$ & $-5.9(-32.0,30.1)$ & $-13.8(-38.5,20.8)$ \\
\hline & p-value & 0.673 & 0.864 & 0.662 & 0.786 & 0.712 & 0.39 \\
\hline \multirow{2}{*}{$\begin{array}{l}\text { Tetrahydrocortisol } \\
\text { (THF) }\end{array}$} & $\%$ change & $-8.23(-30.3,20.8)$ & $-16.9(-37.1,9.7)$ & $-7.2(-29.2,21.8)$ & $-19.8(-39.5,6.2)$ & $-0.2(-24.4,31.7)$ & $-23.7(-42.8,1.9)$ \\
\hline & p-value & 0.542 & 0.192 & 0.592 & 0.125 & 0.989 & 0.069 \\
\hline \multirow[t]{2}{*}{$\alpha$-Cortol } & $\%$ change & $4.7(-25.0,46.1)$ & $9.6(-21.7,53.3)$ & $7.3(-21.2,46.1)$ & $7.3(-22.1,47.7)$ & $2.3(-26.3,42.0)$ & $2.2(-27.3,43.7)$ \\
\hline & p-value & 0.789 & 0.596 & 0.655 & 0.667 & 0.892 & 0.901 \\
\hline \multirow[t]{2}{*}{$\beta$-Cortol } & $\%$ change & $-13.7(-32.9,10.9)$ & $-5.1(-26.3,22.2)$ & $-12.9(-32.2,11.9)$ & $-8.0(-29.0,19.0)$ & $-13.0(-33.2,13.2)$ & $-15.3(-35.5,11.3)$ \\
\hline & p-value & 0.251 & 0.685 & 0.282 & 0.525 & 0.301 & 0.236 \\
\hline \multirow{4}{*}{$\begin{array}{l}\text { Tetrahydrocortisone } \\
\text { (THE) } \\
\alpha \text {-Cortolone }\end{array}$} & $\%$ change & $4.1(-13.9,25.8)$ & $1.9(-15.9,23.4)$ & $4.8(-13.4,26.6)$ & $3.0(-15.4,25.3)$ & $3.5(-14.8,25.6)$ & $-5.9(-23.1,15.2)$ \\
\hline & p-value & 0.681 & 0.848 & 0.632 & 0.772 & 0.732 & 0.557 \\
\hline & $\%$ change & $-1.0(-18.4,20.1)$ & $-7.1(-23.6,13.0)$ & $-0.9(-18.3,20.3)$ & $-10.5(-26.7,9.4)$ & $-3.5(-21.0,17.9)$ & $-18.3(-33.6,0.6)$ \\
\hline & p-value & 0.918 & 0.462 & 0.931 & 0.281 & 0.729 & 0.059 \\
\hline \multirow[t]{2}{*}{$\beta$-Cortolone } & $\%$ change & $25.8(-13.4,82.7)$ & $51.5(3.9,120.8)$ & $26.3(-13.4,8)$ & $53.4(3.9,126.6)$ & $27.6(-15.1,91.8)$ & $51.5(-0.9,131.5)$ \\
\hline & p-value & 0.231 & 0.032 & 0.227 & 0.033 & 0.243 & 0.057 \\
\hline \multirow{4}{*}{$\begin{array}{l}\text { Total sum of } \\
\text { glucocorticoids } \\
\text { Sum of cortisol and } \\
\text { cortisone }\end{array}$} & $\%$ change & $1.7(-13.6,19.8)$ & $5.3(-10.6,24.1)$ & $2.7(-12.6,20.8)$ & $5.3(-10.9,24.4)$ & $0.8(-14.7,19.1)$ & $-2.3(-17.8,16.1)$ \\
\hline & p-value & 0.837 & 0.535 & 0.745 & 0.546 & 0.925 & 0.789 \\
\hline & $\%$ change & $3.7(-14.9,26.2)$ & $20.3(-1.4,46.7)$ & $4.6(-13.9,27.1)$ & $20.5(-1.5,47.4)$ & $1.8(-17.1,25)$ & $19.6(-3.5,48.1)$ \\
\hline & p-value & 0.721 & 0.071 & 0.65 & 0.072 & 0.863 & 0.103 \\
\hline
\end{tabular}

Notes:

a. Results are shown in percent change in concentration $(95 \% \mathrm{CI})$ in comparison with newborns in the low exposure category (i.e. reference category); pvalues $<0.1$ are indicated in bold print.

b. The Basic model was adjusted for sex, gestational age at birth and weight at the time of urine collection.

c. The Adjusted model was further adjusted for maternal smoking during pregnancy, delivery mode, occurrence of vaginal infection, maternal education, existence of older siblings, season at birth and $\mathrm{NO}_{2}$ exposure during pregnancy.

d. Categorized into tertiles (i.e. $<48.4 \mathrm{~dB}$ : low; 48.4-57.9 dB: medium; >57.9 dB: high). 


\section{Figure legends}

Figure 1. Association between road traffic noise (determined by Lden) and the concentration of glucocorticoid metabolites in newborn's urine. Points represent the percent change in concentration derived from full adjusted models compared to newborns in the low exposure (i.e. reference) category; error bars show 95\% CI.

Figure 2. Schematic presentation of hypothesized road traffic noise effects on glucocorticoid metabolites. Stress (i.e. road traffic noise) may exert effects on the hypothalamus-pituitary-adrenal (HPA) axis. This may change the equilibrium between cortisol and cortisone, produced in the adrenal cortex via the enzyme 11ß-hydroxysteroid dehydrogenase (HSD). Cortisol is the active glucocorticoid which binds to the glucocorticoid receptor and induces biological effects, while cortisone is the inactive form. The downstream glucocorticoid metabolites assessed in the urine are produced by enzymatic processes from cortisol and cortisone. The metabolites were measured in the urine of newborns. 


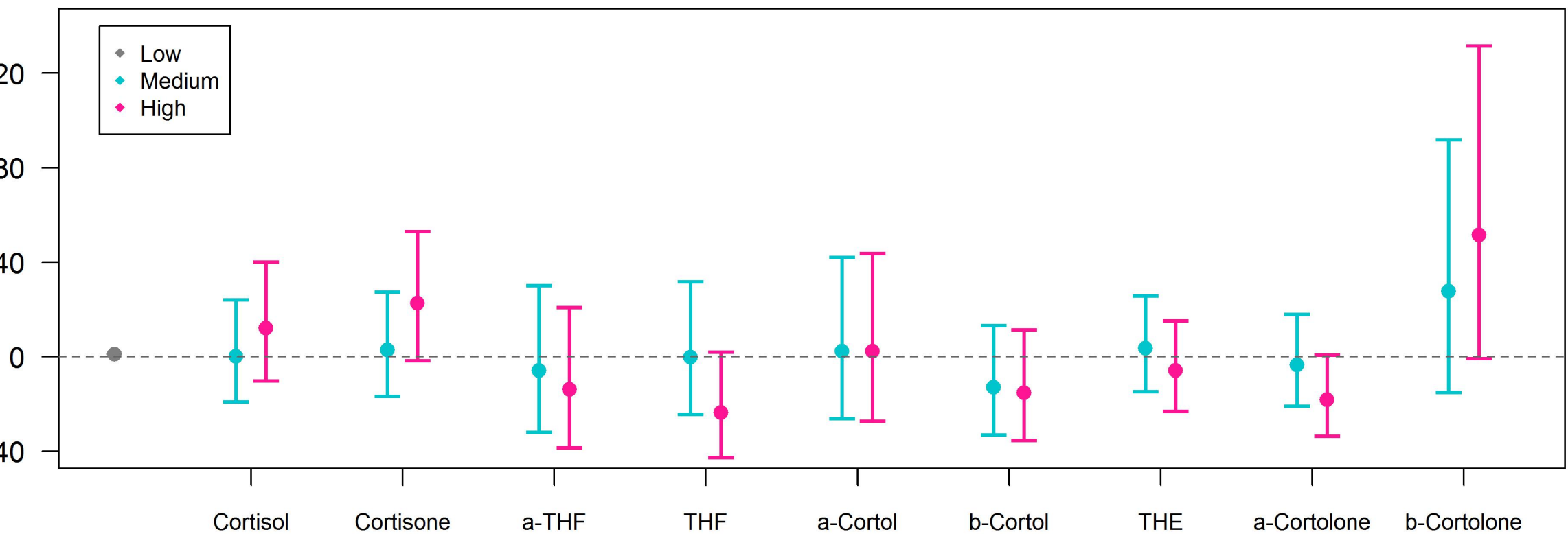




\section{Road traffic noise}

\section{Stress responses}

\section{Hypothalamus-} pituitaryadrenal (HPA) axis

\section{Adrenal cortex}

Cortisol $11 \beta$-HSD (active)

Cortisone (inactive)

\section{Glucoorticoid metabolites}
$\alpha-\mathrm{THF}$
THE
THF
$\alpha$-Cortol
$\alpha$-cortolone
$\beta$-Cortol
$\beta$-cortolone 


\section{Supplemental Material}

\section{Glucocorticoid metabolites in newborns: a marker for traffic noise related stress?}

Manuella Lech Cantuaria ${ }^{1 *}$, Jakob Usemann ${ }^{2,3 *}$, Elena Proietti ${ }^{2,3}$, Victoria Blanes-Vidal ${ }^{1}$, Bernhard Dick $^{4}$, Christa E. Flück ${ }^{5}$, Simone Rüedi ${ }^{2}$, Harris Héritier ${ }^{6,7}$, Jean-Marc Wunderli ${ }^{8}$, Philipp Latzin ${ }^{3}$, Urs Frey $^{2}$, Martin Röösli ${ }^{6,7}$, Danielle Vienneau ${ }^{6,7 \dagger}$ on behalf of the BILD ${ }^{9}$ study group

${ }^{1}$ The Mærsk Mc-Kinney Møller Institute, Faculty of Engineering, University of Southern Denmark, Odense, Denmark

${ }^{2}$ University Children's Hospital Basel (UKBB), Basel, Switzerland.

${ }^{3}$ Pediatric Respiratory Medicine, Department of Pediatrics, Inselspital, Bern University Hospital, University of Bern, Switzerland

${ }^{4}$ Nephrology \& Hypertension, University of Bern, Bern, Switzerland

${ }^{5}$ Pediatric Endocrinology, University Children's Hospital Bern, Bern, Switzerland

${ }^{6}$ Swiss Tropical and Public Health Institute, Basel, Switzerland

${ }^{7}$ University of Basel, Basel, Switzerland

${ }^{8}$ Empa, Laboratory for Acoustics/Noise control, Dübendorf, Switzerland

${ }^{9}$ Basel Bern Infant Lung Development (BILD) cohort, current study group: Insa Korten, Bern; Pinelopi Anagnostopoulou, Bern; Urs Frey, Basel; Olga Gornalova, Basel; Philipp Latzin, Bern; Elena Proietti, Zurich; Jakob Usemann, Basel.

${ }^{*}$ Equal contribution.

${ }^{\dagger}$ Corresponding author.

\section{Contents}

Table S1. Association between road traffic noise (determined by Lden) and concentrations of glucocorticoid metabolites

Table S2. Association between road traffic noise (determined by Leq during the day) and concentrations of glucocorticoid metabolites.

Figure S1. Association between daily road traffic noise and concentrations of glucocorticoid metabolites in newborn's urine.

Table S3. Association between road traffic noise (determined by Leq during the night) and concentrations of glucocorticoid metabolites

Figure S2. Association between nightly road traffic noise and the concentration of glucocorticoid metabolites in newborn's urine

Figure S3. Comparison of the associations based on different traffic noise exposure metrics (i.e. Lden, LeqD and LeqN) and the concentration of each glucocorticoid metabolite 
Table S1. Association between road traffic noise (determined by Lden) and concentrations of glucocorticoid metabolites ${ }^{\text {a }}$

\begin{tabular}{|c|c|c|c|c|c|c|c|}
\hline \multirow{2}{*}{$\begin{array}{l}\text { Cortisol } \\
\text { metabolite }\end{array}$} & & \multicolumn{2}{|c|}{$\begin{array}{c}\text { Crude model } \\
\text { Noise exposure (Lden) level }^{d}\end{array}$} & \multicolumn{2}{|c|}{ 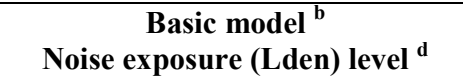 } & \multicolumn{2}{|c|}{$\begin{array}{c}\text { Adjusted model }^{c} \\
\text { Noise exposure (Lden) level }\end{array}$} \\
\hline & & Medium & High & Medium & High & Medium & High \\
\hline \multirow[t]{2}{*}{ Cortisol } & \%change & $2.8(-16.2,26.1)$ & $15.9(-5.7,42.5)$ & $3.8(-15.1,26.9)$ & $15.2(-6.5,41.9)$ & $0.1(-19.2,24.0)$ & $12.1(-10.3,40.1)$ \\
\hline & p-value & 0.795 & 0.162 & 0.717 & 0.185 & 0.991 & 0.316 \\
\hline \multirow[t]{2}{*}{ Cortisone } & $\%$ change & $4.6(-14.7,28.1)$ & $22.4(-0.3,50.2)$ & $5.5(-13.8,29.1)$ & $22.8(-0.4,51.3)$ & $2.8(-16.9,27.2)$ & $22.6(-1.8,53.0)$ \\
\hline & p-value & 0.666 & 0.055 & 0.604 & 0.056 & 0.797 & 0.074 \\
\hline \multirow{2}{*}{ 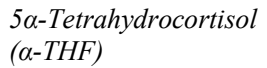 } & $\%$ change & $-6.47(-31.4,27.5)$ & $-2.7(-28.8,33.0)$ & $-6.7(-31.8,27.5)$ & $-4.4(-30.8,32.2)$ & $-5.9(-32.0,30.1)$ & $-13.8(-38.5,20.8)$ \\
\hline & p-value & 0.673 & 0.864 & 0.662 & 0.786 & 0.712 & 0.39 \\
\hline \multirow{2}{*}{$\begin{array}{l}\text { Tetrahydrocortisol } \\
\text { (THF) }\end{array}$} & $\%$ change & $-8.23(-30.3,20.8)$ & $-16.9(-37.1,9.7)$ & $-7.2(-29.2,21.8)$ & $-19.8(-39.5,6.2)$ & $-0.2(-24.4,31.7)$ & $-23.7(-42.8,1.9)$ \\
\hline & p-value & 0.542 & 0.192 & 0.592 & 0.125 & 0.989 & 0.069 \\
\hline \multirow[t]{2}{*}{$\alpha$-Cortol } & $\%$ change & $4.7(-25.0,46.1)$ & $9.6(-21.7,53.3)$ & $7.3(-21.2,46.1)$ & $7.3(-22.1,47.7)$ & $2.3(-26.3,42.0)$ & $2.2(-27.3,43.7)$ \\
\hline & p-value & 0.789 & 0.596 & 0.655 & 0.667 & 0.892 & 0.901 \\
\hline \multirow[t]{2}{*}{$\beta$-Cortol } & $\%$ change & $-13.7(-32.9,10.9)$ & $-5.1(-26.3,22.2)$ & $-12.9(-32.2,11.9)$ & $-8.0(-29.0,19.0)$ & $-13.0(-33.2,13.2)$ & $-15.3(-35.5,11.3)$ \\
\hline & p-value & 0.251 & 0.685 & 0.282 & 0.525 & 0.301 & 0.236 \\
\hline \multirow{4}{*}{$\begin{array}{l}\text { Tetrahydrocortisone } \\
\text { (THE) } \\
\alpha \text {-Cortolone }\end{array}$} & $\%$ change & $4.1(-13.9,25.8)$ & $1.9(-15.9,23.4)$ & $4.8(-13.4,26.6)$ & $3.0(-15.4,25.3)$ & $3.5(-14.8,25.6)$ & $-5.9(-23.1,15.2)$ \\
\hline & p-value & 0.681 & 0.848 & 0.632 & 0.772 & 0.732 & 0.557 \\
\hline & $\%$ change & $-1.0(-18.4,20.1)$ & $-7.1(-23.6,13.0)$ & $-0.9(-18.3,20.3)$ & $-10.5(-26.7,9.4)$ & $-3.5(-21.0,17.9)$ & $-18.3(-33.6,0.6)$ \\
\hline & p-value & 0.918 & 0.462 & 0.931 & 0.281 & 0.729 & 0.059 \\
\hline \multirow[t]{2}{*}{$\beta$-Cortolone } & $\%$ change & $25.8(-13.4,82.7)$ & $51.5(3.9,120.8)$ & $26.3(-13.4,8)$ & $53.4(3.9,126.6)$ & $27.6(-15.1,91.8)$ & $51.5(-0.9,131.5)$ \\
\hline & p-value & 0.231 & 0.032 & 0.227 & 0.033 & 0.243 & 0.057 \\
\hline Total sum of & $\%$ change & $1.7(-13.6,19.8)$ & $5.3(-10.6,24.1)$ & $2.7(-12.6,20.8)$ & $5.3(-10.9,24.4)$ & $0.8(-14.7,19.1)$ & $-2.3(-17.8,16.1)$ \\
\hline glucocorticoids & p-value & 0.837 & 0.535 & 0.745 & 0.546 & 0.925 & 0.789 \\
\hline Sum of cortisol and & $\%$ change & $3.7(-14.9,26.2)$ & $20.3(-1.4,46.7)$ & $4.6(-13.9,27.1)$ & $20.5(-1.5,47.4)$ & $1.8(-17.1,25)$ & $19.6(-3.5,48.1)$ \\
\hline cortisone & $\mathrm{p}$-value & 0.721 & 0.071 & 0.65 & $\mathbf{0 . 0 7 2}$ & 0.863 & 0.103 \\
\hline
\end{tabular}

Notes:

a. Results are shown in percent change in concentration $(95 \% \mathrm{CI})$ in comparison with newborns in the low exposure category (i.e. reference category); p-values $<0.1$ are indicated in bold print.

b. The Basic model was adjusted for sex, gestational age at birth and weight at the time of urine collection.

c. The Adjusted model was further adjusted for maternal smoking during pregnancy, delivery mode, occurrence of vaginal infection, maternal education, existence of older siblings, season at birth and $\mathrm{NO}_{2}$ exposure during pregnancy.

d. Categorized into tertiles (i.e. $<48.4$ : low; 48.4-57.9: medium; >57.9: high). 
Table S2. Association between road traffic noise (determined by Leq during the day) and concentrations of glucocorticoid metabolites ${ }^{\text {a }}$

\begin{tabular}{|c|c|c|c|c|c|c|c|}
\hline \multirow{2}{*}{$\begin{array}{l}\text { Cortisol } \\
\text { metabolites }\end{array}$} & \multirow[b]{3}{*}{$0 /$ chance } & \multicolumn{2}{|c|}{$\begin{array}{c}\text { Crude model } \\
\text { Noise exposure (LeqD) level }^{d}\end{array}$} & \multicolumn{2}{|c|}{$\begin{array}{c}\text { Basic model }^{\mathrm{b}} \\
\text { Noise exposure (LeqD) level }^{\mathrm{d}}\end{array}$} & \multicolumn{2}{|c|}{$\begin{array}{c}\text { Adjusted model }^{\mathrm{c}} \\
\text { Noise exposure (LeqD) level }^{\mathrm{d}}\end{array}$} \\
\hline & & Medium & High & Medium & High & Medium & High \\
\hline Cortisol & & $2.1(-16.9,25.3)$ & $16.4(-5.2,42.9)$ & $4.2(-14.9,27.6)$ & $14.3(-7.0,40.5)$ & $1.1(-18.4,25.3)$ & $10.6(-11.3,37.9)$ \\
\hline & p-value & 0.844 & 0.148 & 0.692 & 0.206 & 0.92 & 0.374 \\
\hline Cortisone & $\begin{array}{l}\text { \%change } \\
\text { p-value }\end{array}$ & $\begin{array}{c}5.7(-13.9,29.7) \\
0.597\end{array}$ & $\begin{array}{c}20.7(-1.6,48.1) \\
0.073\end{array}$ & $\begin{array}{c}7.5(-12.3,31.8) \\
0.487\end{array}$ & $\begin{array}{c}19.6(-2.8,47.2) \\
0.092\end{array}$ & $\begin{array}{c}5.5(-14.8,30.7) \\
0.624\end{array}$ & $\begin{array}{c}18.6(-4.9,47.8) \\
0.132\end{array}$ \\
\hline $\begin{array}{l}5 \alpha \text {-Tetrahydrocortisol } \\
(\alpha-T H F)\end{array}$ & $\begin{array}{l}\text { \%change } \\
\text { p-value }\end{array}$ & $\begin{array}{l}-4.6(-30.1,30.3) \\
0.768\end{array}$ & $\begin{array}{c}-4.7(-30.2,30.1) \\
0.763\end{array}$ & $\begin{array}{c}-5.3(-30.9,29.8) \\
0.736\end{array}$ & $\begin{array}{l}-6.1(-31.8,29.4) \\
0.703\end{array}$ & $\begin{array}{c}-6.1(-32.1,30.0) \\
0.707\end{array}$ & $\begin{array}{c}-13.5(-38.1,20.8) \\
0.396\end{array}$ \\
\hline $\begin{array}{l}\text { Tetrahydrocortisol } \\
(T H F)\end{array}$ & $\begin{array}{l}\text { \%change } \\
\text { p-value }\end{array}$ & $\begin{array}{c}-9.3(-31.2,19.7) \\
0.493\end{array}$ & $\begin{array}{c}-15.9(-36.2,11.0) \\
0.223\end{array}$ & $\begin{array}{c}-7.3(-29.5,21.9) \\
0.587\end{array}$ & $\begin{array}{c}-19.3(-38.9,6.6) \\
0.133\end{array}$ & $\begin{array}{c}-3.1(-26.7,28.2) \\
0.827\end{array}$ & $\begin{array}{c}-20.6(-40.4,5.9) \\
0.118\end{array}$ \\
\hline$\alpha$-Cortol & $\begin{array}{l}\text { \%change } \\
\text { p-value }\end{array}$ & $\begin{array}{c}1.2(-27.6,41.3) \\
0.948\end{array}$ & $\begin{array}{l}13.3(-18.9,58.3) \\
0.465\end{array}$ & $\begin{array}{c}7.1(-21.6,46.1) \\
0.668\end{array}$ & $\begin{array}{c}7.6(-21.6,47.6) \\
0.652\end{array}$ & $\begin{array}{c}2.3(-26.3,42.0) \\
0.894\end{array}$ & $\begin{array}{c}2.2(-27.0,43.3) \\
0.898\end{array}$ \\
\hline$\beta$-Cortol & $\begin{array}{l}\text { \%change } \\
\text { p-value }\end{array}$ & $\begin{array}{l}-14.4(-33.5,10.2) \\
0.229\end{array}$ & $\begin{array}{c}-4.6(-25.8,22.7) \\
0.716\end{array}$ & $\begin{array}{l}-13.7(-33.0,11.0) \\
0.253\end{array}$ & $\begin{array}{l}-7.3(-28.2,19.7) \\
0.561\end{array}$ & $\begin{array}{l}-14.2(-34.1,11.7) \\
0.257\end{array}$ & $\begin{array}{l}-13.9(-34.3,12.8) \\
0.28\end{array}$ \\
\hline $\begin{array}{l}\text { Tetrahydrocortisone } \\
\text { (THE) }\end{array}$ & $\begin{array}{l}\text { \%change } \\
\text { p-value }\end{array}$ & $\begin{array}{c}1.8(-15.9,23.2) \\
0.854\end{array}$ & $\begin{array}{c}4.2(-13.9,26.1) \\
0.672\end{array}$ & $\begin{array}{c}3.2(-14.7,25.0) \\
0.744\end{array}$ & $\begin{array}{c}4.6(-13.9,27.1) \\
0.648\end{array}$ & $\begin{array}{c}1.3(-16.6,23.0) \\
0.898\end{array}$ & $\begin{array}{c}-3.4(-20.9,18.1) \\
0.738\end{array}$ \\
\hline$\alpha$-Cortolone & $\begin{array}{l}\text { \%change } \\
\text { p-value }\end{array}$ & $\begin{array}{c}-1.4(-18.8,19.8) \\
0.89\end{array}$ & $\begin{array}{c}-6.6(-23.1,13.4) \\
0.49\end{array}$ & $\begin{array}{c}-1.2(-18.7,20.0) \\
0.901\end{array}$ & $\begin{array}{c}-9.8(-26.0,10.0) \\
0.311\end{array}$ & $\begin{array}{c}-4.3(-21.7,16.9) \\
0.666\end{array}$ & $\begin{array}{c}-17.1(-32.6,1.9) \\
0.076\end{array}$ \\
\hline$\beta$-Cortolone & $\begin{array}{l}\text { \%change } \\
\text { p-value }\end{array}$ & $\begin{array}{l}23.9(-14.8,80.3) \\
0.263\end{array}$ & $\begin{array}{l}53.2(5.3,122.8) \\
0.027\end{array}$ & $\begin{array}{l}25.0(-14.5,82.6) \\
0.251\end{array}$ & $\begin{array}{c}54.1(4.8,126.6) \\
0.029\end{array}$ & $\begin{array}{l}26.7(-15.8,90.5) \\
0.258\end{array}$ & $\begin{array}{l}52.2(0.0,131.5) \\
0.052\end{array}$ \\
\hline $\begin{array}{l}\text { Total sum of } \\
\text { glucocorticoids }\end{array}$ & $\begin{array}{l}\text { \%change } \\
\text { p-value }\end{array}$ & $\begin{array}{c}0.3(-14.8,18.2) \\
0.97\end{array}$ & $\begin{array}{c}6.7(-9.3,25.6) \\
0.434\end{array}$ & $\begin{array}{l}2.0(-13.3,20.1) \\
0.808\end{array}$ & $\begin{array}{c}5.9(-10.2,24.9) \\
0.494\end{array}$ & $\begin{array}{c}-0.2(-15.6,17.9) \\
0.977\end{array}$ & $\begin{array}{c}-1.1(-16.6,17.3) \\
0.899\end{array}$ \\
\hline $\begin{array}{l}\text { Sum of cortisol and } \\
\text { cortisone }\end{array}$ & $\begin{array}{l}\text { \%change } \\
\text { p-value }\end{array}$ & $\begin{array}{c}4.3(-14.5,27.1) \\
0.678\end{array}$ & $\begin{array}{c}19.2(-2.2,45.3) \\
0.084\end{array}$ & $\begin{array}{c}6.2(-12.7,29.3) \\
0.547\end{array}$ & $\begin{array}{c}17.9(-3.5,44) \\
0.109\end{array}$ & $\begin{array}{l}4.1(-15.3,28) \\
0.705\end{array}$ & $\begin{array}{c}16.2(-6.1,43.7) \\
0.168\end{array}$ \\
\hline
\end{tabular}

a. Results are shown in percent change in concentration $(95 \% \mathrm{CI})$ in comparison with newborns in the low exposure category (i.e. reference category); p-values $<0.1$ are indicated in bold print.

b. The Basic model was adjusted for sex, gestational age at birth and weight at the time of urine collection.

c. The Adjusted model was further adjusted for maternal smoking during pregnancy, delivery mode, occurrence of vaginal infection, maternal education, existence of older siblings, season at birth and $\mathrm{NO}_{2}$ exposure during pregnancy.

d. Categorized into tertiles (i.e. $<46.8$ : low; 46.8-56.2: medium; $>56.2$ : high).

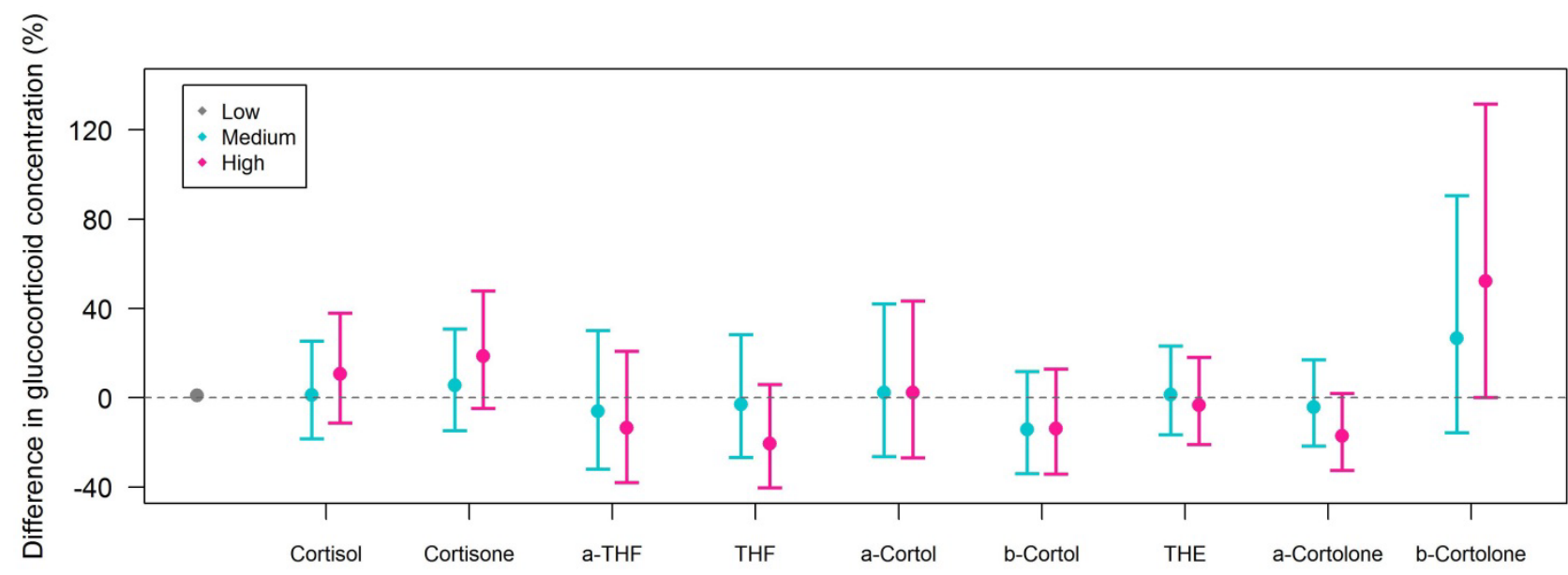

Figure S1. Association between daytime road traffic noise and the concentration of glucocorticoid metabolites in newborn's urine. Points represent the percent change in concentration derived from full adjusted models in comparison to newborns in the low exposure (i.e. reference) category; error bars show $95 \%$ CI. 

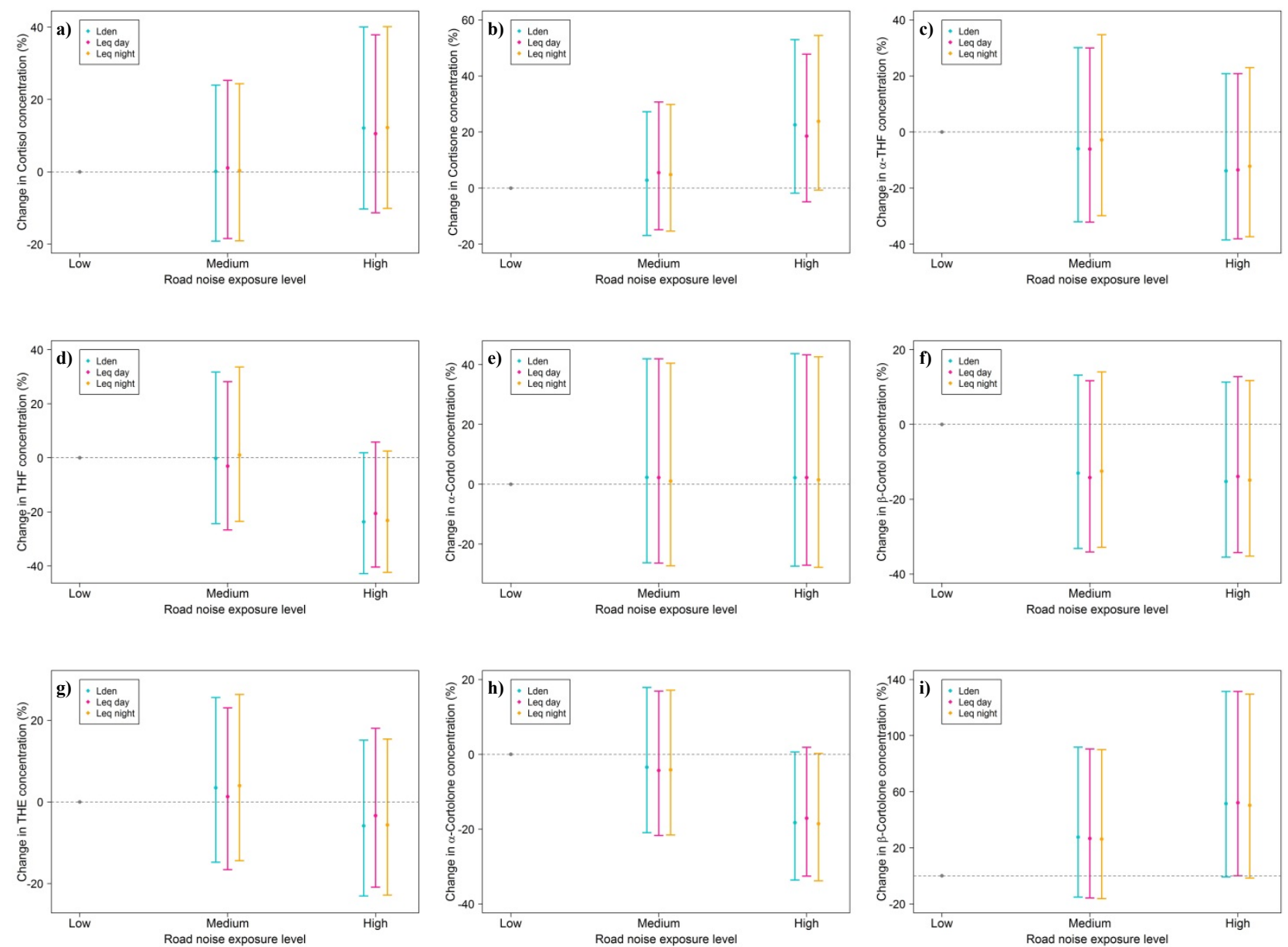

Figure S3. Comparison of the associations for the different traffic noise exposure metrics (i.e. Lden, LeqD and LeqN) and the concentration of each glucocorticoid metabolite: a) cortisol; b) cortisone, c)

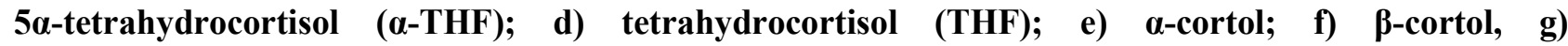
tetrahydrocortisone (THE); h) $\alpha$-cortolone; i) $\beta$-cortolone. Points represent the percent change in concentration; error bars show 95\% CI. Reference category: low noise exposure. Full adjusted models. 